\title{
A Comparative Radiographic Analysis of Fusion Rate between L4-5 and L5-S1 in a Single Level Posterior Lumbar Interbody Fusion
}

\author{
Sang-Hyun Han, Seung-Jae Hyun, Tae-Ahn Jahng, Ki-Jeong Kim \\ Department of Neurosurgery, Spine Center, Seoul National University Bundang Hospital, Seoul National University \\ College of Medicine, Seongnam, Korea
}

\begin{abstract}
Objective: This study aimed to investigate radiographic fusion rates at L4-5 and L5-S1 after single level posterior lumbar interbody fusion (PLIF) and evaluate the relationship between fusion rates and preoperative disc slope angle (DSA), lumbar lordosis (LL), segmental angle (SA), and pelvic parameters.

Methods: We conducted a retrospective review of patients who underwent single level PLIF at L4-5 or L5-S1 during May 2003December 2012 at our institution. 73 patients were finally enrolled. Fusion was assessed by use of the Brantigan-Steffee classification, less than $2 \mathrm{~mm}$ translation and less than $5^{\circ}$ motion on the flexion-extension lateral radiographs. We analyzed the radiographic fusion rates, risk factors, and relationship of fusion rates with DSA, LL, SA, and pelvic parameters.

Results: There were 59 patients (80.8\%) in the L4-5 group and 14 (19.2\%) in L5-S1 (average follow-up, 34 months). The radiographic fusion rates were $89.8 \%$ in the L4-5 group (53/59) and $42.9 \%$ in L5-S1 $(6 / 14)(p<0.001)$. The preoperative DSA was significantly lesser in the L4-5 group than in the L5-S1 group $\left(13.1 \pm 8.1^{\circ}\right.$ vs. $\left.27.2 \pm 6.7^{\circ}, p<0.001\right)$. The $L L, S A$, and pelvic parameters were not related with radiographic fusion rates in both groups. Risk factors for non-union were not identified between the two groups except for the surgery level $(p<0.001)$.

Conclusion: The radiographic fusion rate at L5-S1 was less than half that at L4-5 after single level PLIF. This may be due to the anatomical and biomechanical differences between the two levels. More vigorous effort to achieve successful fusion at L5-S1 should be considered.
\end{abstract}

Key Words: Spinal fusion $\cdot$ Lumbosacral region $\cdot$ Retrospective studies

\section{INTRODUCTION}

The posterior lumbar interbody fusion (PLIF) technique has evolved over the years and has been widely accepted for the management of various lumbar spine pathologies including degenerative disc diseases, spinal stenosis, and spondylolistheses since its first description by Ralph B. Cloward in $1953^{23)}$. Use of instrumentation such as pedicle screws and intervertebral fusion cages has been added to this technique to improve the fusion rates ${ }^{1}$. In literature, radiologic fusion rates for single

\footnotetext{
- Received: April 24, 2015 - Revised: June 11, 2015

- Accepted: June 12, 2015

Corresponding Author: Ki-Jeong Kim, MD

Department of Neurosurgery, Spine Center, Seoul National University

Bundang Hospital, Seoul National University College of Medicine, 166

Gumi-ro, Bundang-gu, Seongnam-si, Gyeonggi 463-707, Korea

Tel: +82-31-787-7166, Fax: +82-31-787-4097

E-mail: kijeong@snu.ac.kr

$\otimes$ This is an Open Access article distributed under the terms of the Creative Commons Attribution Non-Commercial License (http://creativecommons.org/ licenses/by-nc/3.0/) which permits unrestricted non-commercial use, distribution, and reproduction in any medium, provided the original work is properly cited.
}

level PLIF vary between $71 \%$ and $96 \% \%^{1,11,17,24,29)}$. True pseudoarthrosis, a failed bony fusion at the attempted functional spinal unit, has deleterious effects on the postoperative outcome, which include segmental instability, persistent or recurrent back or leg pain, and hardware failure ${ }^{5,26}$. Therefore, it is important to achieve solid fusion for a successful clinical outcome following PLIF surgery, although there is a discrepancy between the radiologic fusion rate and clinical outcomes, ${ }^{1,20)}$ of spinal fusion surgery.

The pelvic parameters include pelvic incidence (PI), sacral slope (SS), and pelvic tilt (PT). Among these three factors, PI is the only constant parameter, closely related with the SS and PT, and has a positive correlation with lumbar lordosis (LL) ${ }^{18)}$. These mean that the pelvic parameters are main axis of the sagittal balance of the spine ${ }^{15)}$; however, there is no report on the relationship between pelvic parameters and lumbosacral interbody fusion.

The most common levels for PLIF are the L4-5 and L5-S1 segments. These two segments, however, differ in their anatomical and biomechanical aspects ${ }^{13,19,27}$. The fusion rates of individual segments have not been sufficiently studied yet. Furthermore, most authors have studied the relationship between 
fusion rates and clinical characteristics of patients or surgical methods $^{8,10,12,25,28)}$. To our knowledge, there is no report on the relationship between $\mathrm{L}$, segmental angle (SA), and pelvic parameters of lumbar spine and the fusion rates of PLIF surgery.

This study aimed to evaluate the individual radiographic fusion rates of single level PLIF procedure at the L4-5 and L5-S1 levels and their relationship with LL, SA, and pelvic parameters of the lumbar spine.

\section{MATERIALS AND METHODS}

\section{Study Design}

This was a retrospective study of patients who had undergone single level PLIF at lumbar spine from January 2003 to December 2012 at our institute. A total of 416 patients were identified, and the inclusion criteria were as follows: (1) degenerative lumbar spinal stenosis or degenerative or isthmic lumbar spondylolisthesis, (2) failed conservative management, (3) index surgical level of L4-L5 or L5-S1, (4) single level instrumented PLIF using bilateral interbody fusion cages and pedicle screws, and (5) a minimum radiographic follow-up period of 12 months, including flexion and extension lateral studies. The exclusion criteria were presence of trauma, infection, tumor, multi-level surgery, unilateral instrumentation, and revision surgeries.

Baseline data were obtained from the patients' medical records. Preoperative radiographic investigations included standing anterior/posterior (AP) and lateral radiographs (including flexion and extension views) of the lumbar spine, bone Dualenergy X-ray absorptiometry (DEXA) scan, as well as magnetic

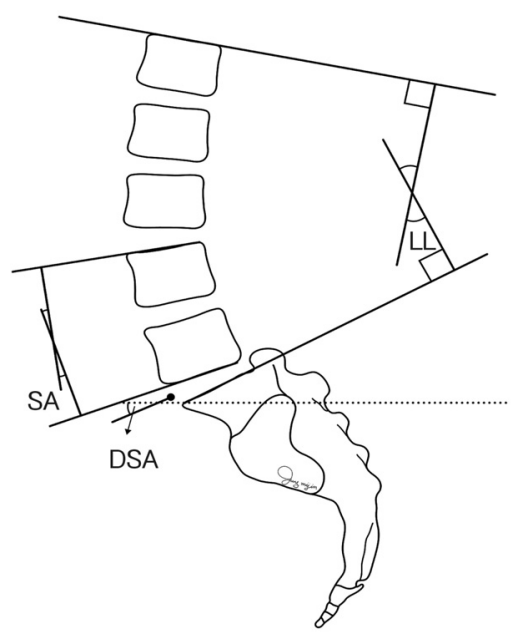

Fig. 1. Artistic illustrations depicting the disc slope angle (DSA), lumbar lordosis (LL), and segmental angle (SA). resonance imaging (MRI) and/or computed tomography (CT) of the lumbar spine. Postoperative radiographs were performed at immediate operative period, 1-, 6-, 12- months after initial surgery, and annually during later follow-up periods.

\section{Radiographic Assessment}

We measured the disc slope angle (DSA), LL, SA, and pelvic parameters in preoperative radiographs.

The DSA was measured as the angle between the line connecting the midpoint of anterior disc space to the midpoint of posterior disc space and a horizontal line. LL was measured between the superior endplate of L1 and the upper endplate of the sacrum, and the SA was measured from the superior endplate of the upper vertebra to the inferior endplate of the lower vertebra. However, the SA of the L5-S1 level was measured between the superior end plate of L5 and the upper endplate of the sacrum (Fig. 1). The PI was measured as the angle between the line perpendicular to the sacral plate at its midpoint and the line connecting this point to the axis of the femoral heads. The SS was measured as the angle between the superior plate of S1 and a horizontal line. The PT was measured as the angle between the line connecting the midpoint of the sacral plate to the femoral heads axis and the vertical line (Fig. 2).

The preoperative DSA, LL, SA, and pelvic parameters ${ }^{4,15)}$ were measured manually using PACS (Infinitt Healthcare Co., Seoul, Korea). The angular parameters were expressed in degrees.

We used the Brantigan-Steffee classification ${ }^{6}$ (Table 1) to assess the trabecular bone formation on the 12-month postoperative AP and lateral radiographs. We measured the translational motion and SA of the index segment on the 12-month postoperative flexion-extension radiographs.

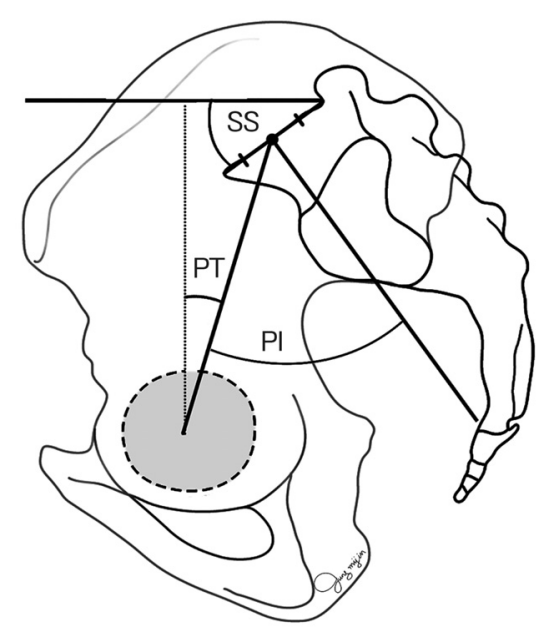

Fig. 2. Artistic illustrations depicting the pelvic incidence (PI), sacral slope (SS), and pelvic tilt (PT). 
Fusion was defined as Brantigan-Steffee classification D or E, translation movement less than $2 \mathrm{~mm}$ and SA less than $5^{\circ}$. Non-union was defined as all conditions except the fusion.

All radiographs were independently interpreted by two spine surgeons (one senior staff and one resident).

\section{Surgical Approach}

The skin incision was made in the midline of the back, and subperiosteal dissection of the multifidus muscle was performed. After complete bone exposure, total laminectomy or bilateral laminotomy and subtotal or total facetectomies were performed under microscopic visualization. Bone grafts of adequate quantity and quality were obtained from the spinous process, lamina, and enlarged superior and inferior articular processes bilaterally. Then, the ligamentum flavum was resected, and the nerve roots were retracted medially. Complete discectomy was performed, following which the disc space was sequentially distracted, and the endplates were prepared.

Table 1. Brantigan-Steffee classification

Classifi-
cation $\quad \begin{aligned} & \text { Description } \\ & \text { A } \\ & \text { loss of disc height, vertebral slip, broken screws, dis- } \\ & \text { placement of the carbon cage, resorption of bone } \\ & \text { graft } \\ & \text { Probable significant resorption of the bone graft due } \\ & \text { to pseudoarthrosis, major lucency, or gap visible in } \\ & \text { fusion area (2 mm around the entire periphery of } \\ & \text { graft). } \\ & \text { Uncertain non-union, bone graft visible in the fusion } \\ & \text { area at approximately the density originally achieved } \\ & \text { at surgery. } \\ & \text { A small lucency or gap may be visible involving a } \\ & \text { portion of the fusion area with at least half of the } \\ & \text { graft area } \\ & \text { Probable fusion bone bridges entire fusion area with } \\ & \text { at least the density achieved at surgery. } \\ & \text { There should be no lucency between the donor and } \\ & \text { vertebral bone. } \\ & \text { Fusion bone in the fusion area is radiographically } \\ & \text { more dense and mature than originally achieved by } \\ & \text { surgery. } \\ & \text { Optimally, there is no interface between the donor } \\ & \text { bone and the vertebral bone, although a sclerotic } \\ & \text { line between the graft and vertebral bone indicates } \\ & \text { fusion. Other signs of solid fusion include mature } \\ & \text { bony trabeculae bridging the fusion area, resorption } \\ & \text { of the anterior traction spur, anterior progression } \\ & \text { of the graft within disc space, and fusion of facet } \\ & \text { joints. }\end{aligned}$

After completion of central and/or foraminal decompression, two interbody cages filled with morselized local bone chips were placed bilaterally, and morselized local bone chips were packed between the cages. After the placement of interbody cages and autologous bone graft, pedicle screw-rod instrumentation was performed using the conventional technique. Meticulous hemostasis, placement of drain, and layered wound closure were performed serially.

\section{Statistical Analysis}

Data were expressed as mean \pm standard deviation in continuous variation or as the number of patients with the percentage in categorical variation. The baseline data, preoperative DSA, LL, SA, and pelvic parameters for fusion and non-union were analyzed using either the chi-square test or Mann-Whitney test. A $p<0.05$ was considered significant. All statistical analyses were performed using the SPSS version 21.0 (IBM Corporation, Armonk, NY, USA).

\section{RESULTS}

A total of 73 patients met the inclusion criteria, of which 59 patients $(80.8 \%)$ were operated at the L4-L5 level (L4-5 group) and $14(19.2 \%)$ at the L5-S1 level (L5-S1 group). The study included 21 men and 52 women with an average age of 61.8 years (range $42-78$ years). The mean duration of followup was 34 months (range 12-102 months). Twenty-two patients had lumbar spinal stenosis without spondylolisthesis, 47 patients had lumbar spinal stenosis with spondylolisthesis, and 4 patients had spondylolisthesis.

The distribution of age, sex, body mass index (BMI), diabetes mellitus (DM), hypertension (HTN), smoking history, and bone mineral density (BMD) was not significantly different between the two groups (Table 2). According to the diagnosis, L4-5 group had 14 cases of spinal stenosis (23.7\%), 41 of spinal stenosis with spondylolisthesis (69.5\%), and 4 of spondylolisthesis (6.8\%). On the other hand, the L5-S1 group had 8 cases of spinal stenosis $(57.1 \%)$ and 6 of spinal stenosis with spondylolisthesis (42.9\%). The disease category of the two groups was statistically different $(p=0.041$, Table 2).

The DSA of the L4-5 group was lower than half that of the L5-S1 group $\left(13.1 \pm 8.1^{\circ}\right.$ vs. $\left.27.2 \pm 6.7^{\circ}, \mathrm{p}<0.001\right)$ (Table 3). The SA at the L4-5 level was also lower in the L4-5 group than in the L5-S1 group $\left(13.4 \pm 7.9^{\circ}\right.$ vs. $\left.18.8 \pm 7.6^{\circ}, \mathrm{p}=0.014\right)$. However, the SA of L5-S1 was not different between the two groups. LL, PI, and SS were not different between the two groups (Table 3).

The radiographic fusion rates at postoperative 12 months 
were $89.8 \%$ (53 of 59 ) in the L4-5 group and 42.9\% (6 of $14)$ in the L5-S1 group $(\mathrm{p}<0.001$, Table 4.). Fig. 3 and 4 showed the example of the fusion and the non-union.

Among the clinical characteristics of the patients, according to radiographic fusion or non-union, age, sex, BMI, DM, HTN, smoking history, BMD, and disease category were not significant. However, the level of surgery was significant $(\mathrm{p}<0.001$, Table 4). The preoperative LL, SA, and pelvic parameters showed no statistical difference between radiographic fusion and non-union (Table 5). We also evaluated these radiographic

Table 2. Baseline clinical characteristics of the patients (according to the levels)

\begin{tabular}{|c|c|c|c|}
\hline Parameters & L4-5 group & L5-S1 group & p-value \\
\hline No. of patients & 59 & 14 & \\
\hline Age (yrs) & $61.6 \pm 9.1$ & $62.6 \pm 7.1$ & 0.721 \\
\hline Gender (Male:Female) & $17: 42$ & $4: 10$ & 1.000 \\
\hline $\mathrm{BMI}\left(\mathrm{kg} / \mathrm{m}^{2}\right)$ & $25.1 \pm 3.8$ & $25.3 \pm 3.6$ & 0.684 \\
\hline DM & $6(8.2 \%)$ & $1(1.4 \%)$ & 1.000 \\
\hline HTN & $23(31.5 \%)$ & $4(5.5 \%)$ & 0.468 \\
\hline Smoking history & $7(9.6 \%)$ & $2(2.7 \%)$ & 1.000 \\
\hline BMD (T-score) & $-1.3 \pm 1.5$ & $-1.2 \pm 1.9$ & 0.833 \\
\hline Diagnosis & & & 0.041 \\
\hline Stenosis & 14 & 8 & \\
\hline Stenosis w/o spondylolisthesis & 41 & 6 & \\
\hline Spondylolisthesis & 4 & 0 & \\
\hline
\end{tabular}

Values are expressed as the mean \pm standard deviation or the number of patients with percentage.

BMI, body mass index; DM, diabetes mellitus; HTN, hypertension; BMD: bone mineral density.

Table 3. Preoperative radiographic parameters of the L4-5and L5-S1 groups

\begin{tabular}{lccc}
\hline \hline Parameters & L4-5 group & L5-S1 group & p-value \\
\hline Disc slope angle & $13.1 \pm 8.1^{\circ}$ & $27.2 \pm 6.7^{\circ}$ & 0.000 \\
Lumbar lordosis & $46.9 \pm 13.7^{\circ}$ & $48.5 \pm 15.2^{\circ}$ & 0.492 \\
Segmental angle at L4-5 & $13.4 \pm 7.9^{\circ}$ & $18.8 \pm 7.6^{\circ}$ & 0.014 \\
Segmental angle at L5-S1 & $18.1 \pm 9.2^{\circ}$ & $15.4 \pm 10.8^{\circ}$ & 0.385 \\
Pelvic incidence & $53.5 \pm 8.4^{\circ}$ & $49.6 \pm 8.0^{\circ}$ & 0.170 \\
Sacral slope & $35.1 \pm 8.8^{\circ}$ & $31.4 \pm 7.8^{\circ}$ & 0.170 \\
Pelvic tilt & $18.5 \pm 7.5^{\circ}$ & $18.6 \pm 10.5^{\circ}$ & 0.933 \\
\hline
\end{tabular}

Values are expressed as mean \pm standard deviation.

${ }^{*}$ Disc slope angle measured at index surgical level.

Table 4. Comparison of the clinical characteristics of the patients according to radiographic fusion or non-union

\begin{tabular}{lccc}
\hline \hline Parameters & Fusion & Non-union & p-value \\
\hline No. of patients & 59 & 14 & 0.392 \\
Age (yrs) & $61.4 \pm 8.9$ & $63.6 \pm 7.9$ & 1.000 \\
Gender (Male:Female) & $17: 42$ & $4: 10$ & 0.989 \\
BMl (kg/m²) & $25.2 \pm 3.8$ & $25.1 \pm 3.6$ & 0.333 \\
DM & $7(9.6 \%)$ & $0(0 \%)$ & 0.468 \\
HTN & $23(31.5 \%)$ & $4(5.5 \%)$ & 1.000 \\
Smoking history & $7(9.6 \%)$ & $2(2.7 \%)$ & 0.176 \\
BMD & $-1.4 \pm 1.4$ & $-0.6 \pm 2.0$ & 0.152 \\
Disease category & $15: 40: 4$ & $7: 7: 0$ & 0.000 \\
Level of operation (L4-5:L5-S1 ) & $53: 6$ & $6: 8$ & \\
\hline
\end{tabular}

Values are expressed as mean \pm standard deviation or the number of patients with percentage values.

BMI, body mass index; DM, diabetes mellitus; HTN, hypertension.

${ }^{\S}$ Disease category denotes spinal stenosis, spinal stenosis with spondylolisthesis, and spondylolisthesis, which are separated by colons. 
parameters in each group according to the fusion status. The preoperative DSA, LL, SA, and pelvic parameters were not statistically different according to the radiographic fusion in both groups (Table 6).

\section{DISCUSSION}

\section{Radiographic Fusion Rate}

PLIF may be regarded as a more reliable surgical approach for spinal instability than posterolateral fusion because it provides more stable biomechanical conditions in the fusion bed by the axial support and the physiologic lordotic angle with the use of interbody cages ${ }^{9}$. It also has other advantages such as restoring the disc height, correcting segmental instability, and adequate decompression of the neural elements ${ }^{30)}$. In our institute, most lumbar fusion surgeries for lumbar spinal stenosis or spondylolisthesis have been performed by PLIF rather than posterolateral fusion. However, only a few articles have reported on fusion rates and factors related to single level PLIF. In a study by Aggazzi et al. ${ }^{1)}$, the fusion rate at L4-5 was 96.2\% (25 of 26) and at L5-S1, it was 95.2\% (20 of 21). Ito et al. ${ }^{11)}$ also reported a fusion rate of $96.4 \%$ (80 of 83 ) at L4-5 and
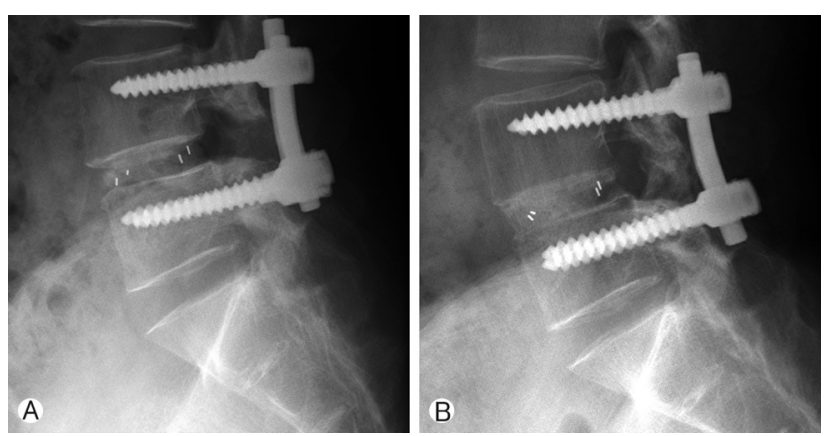

Fig. 3. The immediate postoperative (A) and 1 -year postoperative (B) lateral radiographs of a 59-year-old woman who underwent L4-5 posterior lumbar interbody fusion (PLIF). The 1-year postoperative radiograph (B) showed solid fusion between the vertebral body and the graft.
$87.5 \%$ (7 of 8 ) at L5-S1. In contrast, the fusion rate of the L5-S1 group in our study was much lower than that documented in the literature. This low fusion rate in the L5-S1 group may be due to several factors. Our assessment of the fusion rate was based on radiographs, and it was more difficult to determine bony trabeculation at L5-S1 than at L4-5 in both $\mathrm{AP}$ and lateral radiographs. The relatively smaller number of patients in the L5-S1 group may also have been inadequate for assessment of the fusion rate. We intended to evaluate the influence of individual levels on the fusion rate. With that in mind, we set up the exclusion criteria, and many cases of L5-S1 were eliminated. The surgical techniques of bone grafting and instrumentation also may have played a role in the lower fusion rate of the L5-S1 group. We used the similar amount of local
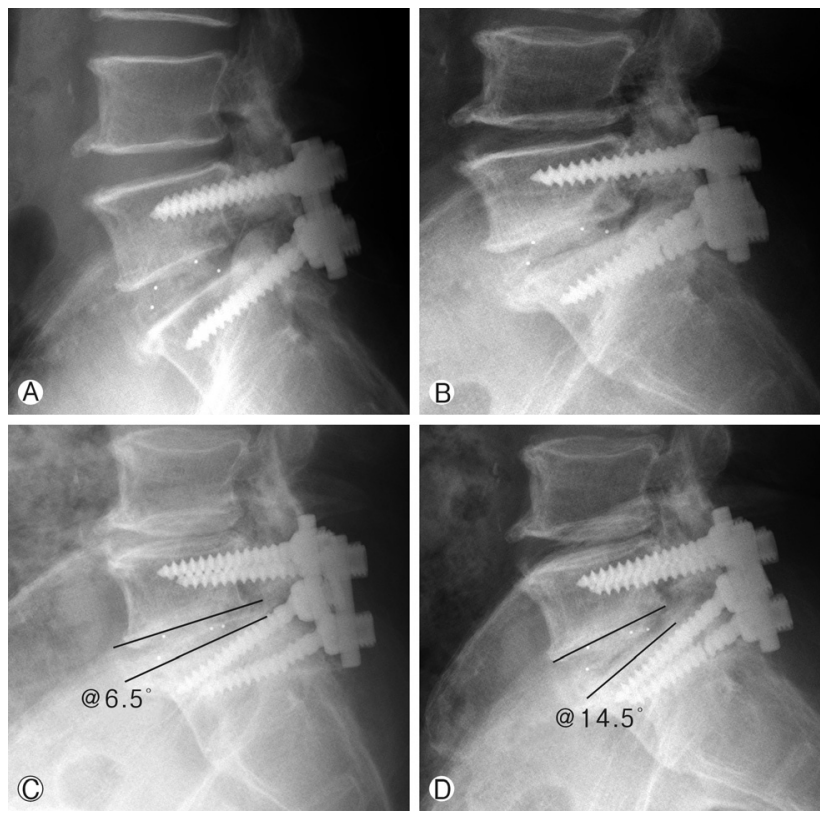

Fig. 4. The immediate postoperative lateral radiographs $(A)$ of a 74-year-old man who underwent L5-S1 posterior lumbar interbody fusion (PLIF). The 1 -year postoperative lateral radiograph (B) revealed a screw fracture, loss of disc height, and a visible gap in the fusion area. The segmental angle difference was $>5^{\circ}$ in the fusion segment between the flexion (C) and extension (D) radiographs at 1 year after the surgery.

Table 5. Preoperative radiographic parameters between fusion and non-union

\begin{tabular}{lccc}
\hline \hline Parameters & Fusion & Non-union & p-value \\
\hline Lumbar lordosis & $47.8 \pm 13.2^{\circ}$ & $44.6 \pm 17.1^{\circ}$ & 0.644 \\
Segmental angle at L4-5 & $14.1 \pm 8.1^{\circ}$ & $16.1 \pm 8.0^{\circ}$ & 0.218 \\
Segmental angle at L5-S1 & $18.4 \pm 9.4^{\circ}$ & $14.5 \pm 9.5^{\circ}$ & 0.223 \\
Pelvic incidence & $53.3 \pm 8.7^{\circ}$ & $50.4 \pm 6.5^{\circ}$ & 0.218 \\
Sacral slope & $35.0 \pm 9.4^{\circ}$ & $31.9 \pm 4.8^{\circ}$ & 0.205 \\
Pelvic tilt & $18.5 \pm 8.8^{\circ}$ & $18.8 \pm 4.8^{\circ}$ & 0.828 \\
\hline
\end{tabular}

Values are expressed as mean \pm standard deviation. 
Fusion Rates between L4-5 and L5-S1 after PLIF

Table 6. The relationship between presence of fusion and preoperative radiographic parameters in the L4-5 and L5-S1 groups

\begin{tabular}{lcccccc}
\hline \hline & & L4-5 group & & L5-S1 group \\
\hline Parameters & Fusion & Non-union & p-value & Fusion & Non-union & p-value \\
\hline No. of patients & 53 & 6 & & 6 & 8 & \\
Disc slope angle & $13.1 \pm 8.2^{\circ}$ & $12.7 \pm 7.1^{\circ}$ & 0.851 & $26.7 \pm 5.0^{\circ}$ & $27.7 \pm 8.0^{\circ}$ & 0.606 \\
Lumbar lordosis & $47.4 \pm 13.2^{\circ}$ & $49.8 \pm 16.5^{\circ}$ & 0.466 & $47.2 \pm 13.5^{\circ}$ & $48.7 \pm 17.6^{\circ}$ & 0.729 \\
Segmental angle at L4-5 & $14.3 \pm 7.9^{\circ}$ & $16.8 \pm 8.7^{\circ}$ & 0.199 & $13.6 \pm 7.8^{\circ}$ & $14.0 \pm 8.6^{\circ}$ & 0.855 \\
Segmental angle at L5-S1 & $17.9 \pm 9.3^{\circ}$ & $17.1 \pm 7.6^{\circ}$ & 0.734 & $18.2 \pm 8.9^{\circ}$ & $18.6 \pm 6.9^{\circ}$ & 0.882 \\
Pelvic incidence & $53.9 \pm 11.1^{\circ}$ & $51.9 \pm 11.6^{\circ}$ & 0.458 & $54.6 \pm 11.3^{\circ}$ & $48.0 \pm 13.5^{\circ}$ & 0.072 \\
Sacral slope & $34.0 \pm 9.2^{\circ}$ & $32.9 \pm 11.9^{\circ}$ & 0.665 & $34.2 \pm 9.5^{\circ}$ & $31.0 \pm 12.5^{\circ}$ & 0.475 \\
Pelvic tilt & $20.2 \pm 10.7^{\circ}$ & $19.1 \pm 8.5^{\circ}$ & 0.666 & $20.7 \pm 10.5^{\circ}$ & $17.0 \pm 9.5^{\circ}$ & 0.255 \\
\hline
\end{tabular}

Values are expressed as mean \pm standard deviation.

"Disc slope angle measured at index surgical level.

bone graft at both levels. The amount and quality of the bone graft may have been inadequate for L5-S1. Nevertheless, our results showed an obvious lower fusion rates at the L5-S1 level than at L4-5 with single level PLIF surgery, because we performed the operations with nearly uniform fashion. In addition, no other factors, except the index surgery level, could have affected the fusion rate.

\section{Anatomical and Biomechanical Differences}

An inferior fusion rate in the L5-S1 group may be due to the anatomical and biomechanical differences between the L4-5 and L5-S1 levels. First, the DSA, which is defined as the angle formed by the disc space and horizontal plane, in the L5-S1 group was two times higher than that in the L4-5 group (27.2 \pm $6.7^{\circ}$ and $13.1 \pm 8.1^{\circ}$, respectively). With an increase in the DSA, the shear force in the disc space also increases. Therefore, this may be a less favorable factor for the fusion rate at the L5-S1 level compared to the L4-5 level. Second, the vertebral compression strength should be considered ${ }^{22}$. As the lordotic curvature of the lumbar spine begins from the L3 or L4 vertebral body, the compression strength of the lumbosacral articular surface may be lower than that of the L5 vertebral body. As a result, the compression strength exerted on the L5-S1 disc space may be weaker than that exerted on L45, and this phenomenon is also disadvantageous for PLIF at L5-S1. The third factor to be considered is the larger range of motion at the L5-S1 segment. In the lumbar spine, flexion and extension motions increase in range from the top to the bottom, and the lumbosacral joint offers more flexion and extension motion than any other lumbar segments ${ }^{3,21)}$. These facts indicate that translational movement between the L5 vertebra and sacral promontory may occur in larger scale than any other lumbar segments after PLIF. The fourth factor is the facet joint orientation between the L5 and S1 vertebrae, which is in a more coronal plane than other lumbar segments ${ }^{13)}$. This facet joint orien- tation is very important for the stability of individual segments. However, we performed total or subtotal resection of bilateral facet joints for adequate foraminal decompression. This wide resection of the facet joints was inevitable for relief from compressive symptoms but may be detrimental for segmental stability and successful bone fusion after PLIF. This issue of facet joint resection may be more important for the L5-S1 segment because facet joint strain on L5-S1 is greater than that at other lumbar spine segments ${ }^{2}$. Finally, the shape of the disc space should be considered. The L5-S1 disc space is conical in shape, with the posterior margin of the disc being narrower than the anterior margin. On the other hand, the disc space in other lumbar spine segments is shaped more like a rectangle. We used fusion cages of the same size and lordotic angle at both levels. Therefore, a contact between the bony end plate and surface of the fusion cage might be less compact and tight at the L5-S1 level than at the L4-5 level. We also experienced some difficulty in packing dense bone graft in the anterior disc space of L5-S1 because of a narrow posterior disc space.

\section{Pelvic Parameters and Bone Fusion}

We also investigated the effect of preoperative pelvic parameters on bone fusion after PLIF. The pelvic parameters are related to the sagittal balance of human spine and may be altered in certain pathologic conditions such as degenerative or isthmic spondylolisthesis ${ }^{16}$. Therefore, we hypothesized that differences in pelvic parameters may influence fusion rates after PLIF. Lee et al. ${ }^{14)}$ studied pelvic parameters in the normal Korean population and reported a PI of $52.5 \pm 4.5^{\circ}$. According to their result, the values of the two groups in this study were within the normal range for the Korean population. Preoperative PI, SS, and PT were not different between the two groups. Although patients with fusion had higher PI, SS, and PT than the non-union cases in each group, the difference was not significant. Our result shows that preoperative pelvic parameters 
are not related with a successful bone fusion after single PLIF regardless of the index level of operation. In other words, the sagittal balance of a patient with degenerative lumbar spinal stenosis or spondylolisthesis is not related with radiographic fusion after single level PLIF.

\section{Suggestions for Successful Bone Fusion at the L5-S1 Level}

As our result showed that the local environment is less favorable for successful bone fusion at the L5-S1 level than other lumbar segments, several technical considerations may be required during the surgery. The first one is the need for more precaution and a delicate procedure for fusion, both of which are achieved thorough denudation of the cartilaginous end plate, compact packing of the bone graft, especially in the anterior disc space, and use of a good quality as well as sufficient amount of bone graft. The second is an optimal instrumentation technique, such as the use of interbody cages that fit the shape of the disc space (lordotic configuration for L5-S1 level), pedicle screws with thicker diameter for S1, and bi-cortical purchase of S1 pedicle screws. The third important consideration is that unless it is absolutely necessary to perform decompression, a bilateral total facetectomy should be avoided.

\section{Limitations of Study}

There are several limitations to this retrospective study. This study was conducted retrospectively. First, the number of enrolled patients was small, and the distribution of patients in each group was unbalanced. The second limitation was anatomical and related to the ilium in the radiographs. In the lateral radiographs, the L5-S1 disc space was more shrouded by the iliac bone than the L4-5. Therefore, confirming the trabeculation was more difficult in the L5-S1 group than in the L4-5 group, and it was also somewhat difficult to clearly confirm the fusion or non-union state. Third, using the CT scan, the fusion rate could be evaluated more accurately than by radiography ${ }^{7}$. However, in this study, a CT scan was not available in some cases, and therefore could not be included as an evaluation method. Our data, however, had a uniform disease category and surgical technique using bone grafting and instrumentation.

\section{CONCLUSION}

The fusion rate at the L5-S1 level was much inferior to that at the L4-5 after single level PLIF. The anatomical and biomechanical aspects of these two levels are different. The pelvic parameters were not statistically significant between L4-5 and
L5-S1 and were unrelated with bone fusion. To attain successful bone fusion at the L5-S1 level with PLIF, one should use good quality and sufficient amount of bone graft, fusion cages that fit well in the disc spaces, and rigid fixation techniques, as well as avoid bilateral total facetectomy, except in inevitable cases.

\section{REFERENCES}

1. Agazzi S, Reverdin A, May D: Posterior lumbar interbody fusion with cages: an independent review of 71 cases. J Neurosurg 91: 186-192, 1999

2. Ames CP, Acosta FL Jr, Chi J, Iyengar J, Muiru W, Acaroglu $\mathrm{E}$, et al: Biomechanical comparison of posterior lumbar interbody fusion and transforaminal lumbar interbody fusion performed at 1 and 2 levels. Spine (Phila Pa 1976) 30:E562-E566, 2005

3. Banton RA: Biomechanics of the spine. J Spinal Research Foundation 7:12-20, 2012

4. Boulay C, Tardieu C, Hecquet J, Benaim C, Mouilleseaux B, Marty C, et al: Sagittal alignment of spine and pelvis regulated by pelvic incidence: standard values and prediction of lordosis. Eur Spine J 15:415-422, 2006

5. Brantigan JW: Pseudarthrosis rate after allograft posterior lumbar interbody fusion with pedicle screw and plate fixation. Spine (Phila Pa 1976) 19:1271-1279, 1994

6. Brantigan JW, Steffee AD: A carbon fiber implant to aid interbody lumbar fusion: two-year clinical results in the first 26 patients. Spine (Phila Pa 1976) 18:2106-2107, 1993

7. Choudhri TF, Mummaneni PV, Dhall SS, Eck JC, Groff MW, Ghogawala Z, et al: Guideline update for the performance of fusion procedures for degenerative disease of the lumbar spine. Part 4: Radiographic assessment of fusion status. J Neurosurg Spine 21:23-30, 2014

8. Christensen FB, Hansen ES, Eiskjær SP, Høy K, Helmig P, Neumann P, et al: Circumferential lumbar spinal fusion with Brantigan cage versus posterolateral fusion with titanium CotrelDubousset instrumentation: a prospective, randomized clinical study of 146 patients. Spine (Phila Pa 1976) 27:2674-2683, 2002

9. Devkota P, Shrestha S, Krishnakumar R, Renjithkumar J: Posterior lumbar interbody fusion for the management of spondylolisthesis. Nepal Med Coll J 13:46-49, 2011

10. Fritzell P, Hägg O, Wessberg P, Nordwall A, Group SLSS: Chronic low back pain and fusion: a comparison of three surgical techniques: a prospective multicenter randomized study from the Swedish lumbar spine study group. Spine (Phila Pa 1976) 27:1131-1141, 2002

11. Ito Z, Matsuyama Y, Sakai Y, Imagama S, Wakao N, Ando K, et al: Bone union rate with autologous iliac bone versus local bone graft in posterior lumbar interbody fusion. Spine (Phila Pa 1976) 35:E1101-E1105, 2010

12. Kim KT, Lee SH, Lee YH, Bae SC, Suk KS: Clinical outcomes of 3 fusion methods through the posterior approach in the lumbar spine. Spine (Phila Pa 1976) 31:1351-1357, 2006

13. Kowalski RJ, Ferrara LA, Benzel EC: Biomechanics of the spine. Neurosurg Q 15:42-59, 2005

14. Lee CS, Chung SS, Chung KH, Kim SR: Significance of pelvic 
incidence in the development of abnormal sagittal alignment. J Korean Orthop Assoc 41:274-280, 2006

15. Legaye J, Duval-Beaupere G, Hecquet J, Marty C: Pelvic incidence: a fundamental pelvic parameter for three-dimensional regulation of spinal sagittal curves. Eur Spine J 7:99-103, 1998

16. Lim JK, Kim SM: Difference of sagittal spinopelvic alignments between degenerative spondylolisthesis and isthmic spondylolisthesis. J Korean Neurosurg Soc 53:96-101, 2013

17. Makino T, Kaito T, Fujiwara H, Ishii T, Iwasaki M, Yoshikawa $\mathrm{H}$, et al: Does fusion status after posterior lumbar interbody fusion affect patient-based QOL outcomes? An evaluation performed using a patient-based outcome measure. J Orthop Sci 19:707-712, 2014

18. Oh SK, Chung SS, Lee CS: Correlation of pelvic parameters with isthmic spondylolisthesis. Asian Spine J 3:21-26, 2009

19. Okoro T, Sell P: A short report comparing outcomes between L4/L5 and L5/S1 single-level discectomy surgery. J Spinal Disord Tech 23:40-42, 2010

20. Okuda S, Oda T, Miyauchi A, Haku T, Yamamoto T, Iwasaki M: Surgical outcomes of posterior lumbar interbody fusion in elderly patients. J Bone Joint Surg Am 88:2714-2720, 2006

21. Panjabi M, Oxland T, Yamamoto I, Crisco J: Mechanical behavior of the human lumbar and lumbosacral spine as shown by three-dimensional load-displacement curves. J Bone Joint Surg Am 76:413-424, 1994

22. Panjabi MM, White AA 3rd: Basic biomechanics of the spine. Neurosurgery 7:76-93, 1980
23. Steffee AD, Sitkowski DJ: Posterior lumbar interbody fusion and plates. Clin Orthop Relat Res 227:99-102, 1988

24. Suh KT, Park WW, Kim SJ, Cho HM, Lee JS, Lee JS: Posterior lumbar interbody fusion for adult isthmic spondylolisthesis a comparison of fusion with one or two cages. J Bone Joint Surg Br 90:1352-1356, 2008

25. Thalgott JS, Fogarty ME, Giuffre JM, Christenson SD, Epstein AK, Aprill C: A prospective, randomized, blinded, single-site study to evaluate the clinical and radiographic differences between frozen and freeze-dried allograft when used as part of a circumferential anterior lumbar interbody fusion procedure. Spine (Phila Pa 1976) 34:1251-1256, 2009

26. Wetzel FT, LaRocca $H$ : The failed posterior lumbar interbody fusion. Spine (Phila Pa 1976) 16:839-845, 1991

27. Yamamoto I, Panjabi M, Oxland T, Crisco J: The role of the iliolumbar ligament in the lumbosacral junction. Spine (Phila $\mathrm{Pa}$ 1976) 15:1138-1141, 1990

28. Yan DL, Pei FX, Li J, Soo CL: Comparative study of PILF and TLIF treatment in adult degenerative spondylolisthesis. Eur Spine J 17:1311-1316, 2008

29. Yoon WS, Cho KS, Park JH, Park CK, Yoo DS, Huh PW, et al: Comparison of clinical outcomes: Posterolateral fusion versus posterior lumbar interbody fusion in low-grade degenerative spondylolisthesis. Korean J Spine 1:481-488, 2004

30. Zhao J, Hou T, Wang X, Ma S: Posterior lumbar interbody fusion using one diagonal fusion cage with transpedicular screw/ rod fixation. Eur Spine J 12:173-177, 2003 